\title{
Treatment adherence and disease burden of individuals with rheumatic diseases admitted as outpatients to a large rheumatology center in Shanghai, China
}

\author{
This article was published in the following Dove Press journal: \\ Patient Preference and Adherence \\ 18 September 2017 \\ Number of times this article has been viewed
}

\author{
Le Zhang' \\ Guo Hong Lu' \\ Shuang $\mathrm{Ye}^{2}$ \\ Bin $\mathrm{Wu}^{\prime}$ \\ Yi Shen ${ }^{3}$ \\ Ting $\mathrm{Li}^{2}$ \\ 'Department of Pharmacy, South \\ Campus, Renji Hospital, School of \\ Medicine, Shanghai Jiaotong University, \\ Shanghai, China; ${ }^{2}$ Department of \\ Rheumatology, South Campus, Renji \\ Hospital, School of Medicine, Shanghai \\ Jiaotong University, Shanghai, China; \\ ${ }^{3}$ Department of Mathematics, Applied \\ Statistics, Shanghai Jiaotong University, \\ Shanghai, China
}

Purpose: The purpose of this study was to determine treatment adherence and disease burden, analyze detailed medication problems experienced by patients, and identify factors associated with adherence in patients with rheumatic diseases in China.

Patients and methods: Patients with confirmed diagnoses of ankylosing spondylitis (AS), rheumatoid arthritis (RA), and systemic lupus erythematosus (SLE) were recruited, regardless of demographics, disease severity, and treatment characteristics. Adherence was assessed using the Compliance Questionnaire for Rheumatology and interview-based self-reports. A backwardsstepwise multivariate regression analysis was used to identify factors associated with adherence. Results: We collected data on 252 patients who had a rheumatic disease and visited our outpatient clinic in January or February of 2017. There were 121 patients with SLE, 70 with RA, and 61 with AS. The overall adherence rate was $41.7 \%$, with $48.7 \%$ for SLE patients, $38.6 \%$ for RA patients, and $31.1 \%$ for AS patients. The overall EuroQol (EQ)-index was 0.761; AS patients had the best EQ-index (0.792), followed by those with SLE (0.780) and RA (0.700). SLE patients also had greater annual direct costs (US\$5,103.58) than RA or AS patients.

Conclusion: Overall, $41.7 \%$ of our rheumatic disease patients were adherent to treatment, lower than in many other parts of the world. This indicates that it is important to identify methods that improve adherence in this population. It is particularly important to improve the health status and reduce the disease burden of patients with SLE, the most common of the three rheumatic diseases we analyzed. Our results suggest that reminder tools may improve adherence. Further prospective research is needed to confirm whether reminder tools and other measures can improve patient compliance.

Keywords: adherence, disease burden, EQ-5D, SLE, rheumatic disease

\section{Introduction}

Rheumatoid arthritis (RA), ankylosing spondylitis (AS), and systemic lupus erythematosus (SLE) are major autoimmune and rheumatic diseases. Patients with any of these chronic conditions need long-term medication(s) to control disease progression. Adherence, defined as the extent to which a patient correctly follows medical advice, also plays an important role. One of the main causes of persistent disease activity may be the lack of adherence to treatment, because "drugs don't work in patients who don't take them". ${ }^{1}$

Previous studies of SLE patients, which had different objectives and methodologies, reported that adherence ranged from $3 \%$ to $76 \%,,^{2-5}$ but there are no such data for
Correspondence: Ting Li Department of Rheumatology, South Campus, Renji Hospital, School of Medicine, Shanghai Jiaotong University, 2000 Jiangyue Road, Shanghai 20III2, China

Tel +86 I39 I6927066

Fax +86 2I 3450615 I

Email leeting007@।63.com 
mainland China. Moreover, chronic rheumatic conditions, such as RA, AS, and SLE, result in substantial burdens for patients and their families. ${ }^{6-10}$ The direct costs of a rheumatic disease can reach US\$71,334.00 per patient per year in the Unites States, and costs are greater in those who develop organ dysfunction (such as lupus nephritis), disease flares, high disease activity, and disease of long duration. ${ }^{11}$ Again, there are limited data on these costs for mainland China. Previous studies estimated the prevalence of SLE in mainland China was $0.30 \%$ to $0.376 \%$, the prevalence of RA in mainland China was $0.2 \%$ to $0.4 \%$, and the prevalence of AS in Guangdong Province of mainland China was $0.38 \% .^{12-14}$ China's population is 1.375 billion, so there may be more than 10 million patients with one of these rheumatic diseases in China. Therefore, it is necessary to identify potential problems with treatment adherence in this population, and to determine the best approaches to resolve these problems.

The aims of this study of patients with rheumatic diseases in China were to determine the burden of rheumatic diseases and patient adherence to treatment; identify the detailed medication problems experienced by these patients; and analyze factors associated with adherence using a multifactor regression analysis.

\section{Material and methods Study design}

This study was conducted at the Outpatient Clinic of Renji Hospital, Shanghai, China. The research protocol was approved by Shanghai Jiaotong University of Medicine, Renji Hospital Ethics Committee (approval no [2016] 216K). This center is one of the largest rheumatology centers in China, and the patients are from all over the country. All participating patients provided written informed consent and completed questionnaires which assessed adherence to treatment, health status, and disease burden.

\section{Recruitment and data collection}

Outpatients using rheumatic drugs were considered for inclusion if they fulfilled the American College of Rheumatology 1987 or 2012 criteria for SLE, RA, or AS and visited the Outpatient Clinic of the South Campus of Renji Hospital in January or February of 2017. Patients were excluded if they were illiterate, had severe mental disorders, or had serious physical constraints. All others were included, regardless of demographics, disease characteristics, or treatment characteristics. Data were collected on demographic characteristics (age, sex, marital status, education level, employment, physical strength, monthly per capita income, and type of medical insurance), disease characteristics (diagnosis, duration, comorbidities, direct costs, indirect costs, and health status based on EuroQol five dimensions [EQ-5D] score), and treatment characteristics (types of pills prescribed daily, use of a glucocorticoid [GC], use of disease modifying antirheumatic drugs [DMARDs], use of non-steroidal antiinflammatory drugs [NSAIDs], use of a biological DMARD, dosing frequency, side effects, Compliance Questionnaire for Rheumatology [CQR] score, use of tools such as medication reminders, and use of alternative medicines [traditional Chinese medicines, physical therapy, herbs, etc.]).

\section{Self-reported adherence}

Adherence was assessed using two self-reported measures: the CQR and an interview-based self-report. The CQR consists of 19 statements concerning medication intake, in which the patient indicates the extent of agreement to each statement using a 4-point Likert scale. ${ }^{15}$ Nonadherence was defined by a CQR score below $80 \% .{ }^{16} \mathrm{CQR}$ only measures adherence indirectly, so an interview-based self-report was also given. During this $10 \mathrm{~min}$ interview, there were two direct questions about each prescribed medication: "Do you sometimes forget a dose?" and "Do you have any confusion about the medications you are taking?". More than one missed dose per month was defined as nonadherence. To analyze specific medication problems, we conducted further interviews, and then summarized these problems into four categories: error in directions; missing dose; unknown precautions; and adjust dosage or stop taking the medicine without doctor's directions. If the prescription for a drug, such as an NSAID, was "as needed" (p.r.n.), then the patient could not be classified as nonadherent for this drug.

\section{Measurement of quality of life}

The general health status of patients was evaluated using the Chinese version of the general population-based three-level EQ-5D-3L questionnaire. ${ }^{17,18}$ Each EQ-5D-3L health state was scored as 1 (no problems), 2 (some/moderate problems), or 3 (extreme problems) to indicate functional levels in five dimensions (mobility, self-care, usual activities, pain/ discomfort, and anxiety/depression). The "time-trade-off", a part of the EQ-5D-index, was also used to assess quality of life.

\section{Disease burden}

The 1-year data of participants who completed the protocol were analyzed, and the average total annual cost per patient was calculated. The direct costs consisted of outpatient 
expenses (laboratory tests, drugs, registered fees, etc., with data collected by invoice); hospitalization expenses (hospital admission fees, laboratory tests, drugs, devices, aids, etc., with data collected by invoice); and non-medical costs (fees for transportation to clinics, community services such as home care, and purchase of adaptive devices, with data collected from self-reports). The indirect costs, with data collected from self-reports, consisted of costs due to time incurred by patients and care givers and costs due to a patient's inability to work.

\section{Statistical analysis}

Descriptive data are presented as means $( \pm \mathrm{SD})$ or numbers (percentages), depending on the distribution of the measured variable. The effects of demographic characteristics, disease characteristics, and treatment characteristics on adherence (determined according to the interview-based self-report) were first assessed using a univariate analysis of group differences, with no correction for multiple testing $(\alpha=0.05)$. We used a chi-square test to evaluate the significance of differences in proportions, and an independent sample $t$-test to evaluate the significance of differences in means. Then, a backwards-stepwise multivariate analysis was performed to account for confounding. All variables that had $P$-values below 0.4 in the univariate analysis were entered into the multivariate model, in which adherence (assessed by the interview-based self-report) was the dependent variable. Data were analyzed using SPSS (version 21.0). All costs were converted into US\$ from CNY at the exchange rate of 6.6423 , the average in 2016 according to the National Bureau of Statistics.

\section{Results}

\section{Demographic and clinical characteristics of the study population}

Table 1 shows the demographic and clinical characteristics of the study population $(n=252)$. A total of 185 patients $(73.4 \%)$ were female and the overall mean $( \pm \mathrm{SD})$ age was $40.1( \pm 15.4)$ years. A total of $76.6 \%$ of the patients were married, $61.1 \%$ were employed, and $56.0 \%$ had a secondary education. A total of 201 (79.8\%) had jobs with little physical activity (office jobs, etc.), and about half of the patients had monthly incomes of 1,000-5,999 Yuan. The per capita disposable income in China was 21,966.19 Yuan per year $(1,830.52$ Yuan per month) in 2015, according to the National Bureau of Statistics.

Analysis of disease characteristics shows that SLE $(48.0 \%)$ was the most common of the three rheumatic
Table I Demographic and clinical characteristics of outpatients with rheumatic diseases $(n=252)$

\begin{tabular}{|c|c|}
\hline Sociodemographic characteristics & n (\%) \\
\hline Age (years), mean (SD) & $40.13(15.39)$ \\
\hline Sex, female & I85 (73.4I) \\
\hline \multicolumn{2}{|l|}{ Marital status } \\
\hline Married & $193(76.58)$ \\
\hline Other marital status & $59(23.4 I)$ \\
\hline \multicolumn{2}{|l|}{ Education level } \\
\hline Primary ( $0-6$ years) & $25(9.92)$ \\
\hline Secondary (7-12 years) & $14 \mid(55.95)$ \\
\hline Higher ( $>12$ years $)$ & $86(34.12)$ \\
\hline \multicolumn{2}{|l|}{ Employment } \\
\hline Employed & $154(61.1 \mathrm{I})$ \\
\hline Unemployed & $98(38.89)$ \\
\hline \multicolumn{2}{|l|}{ Work activity } \\
\hline Low level of activity (office etc) & $20 I(79.76)$ \\
\hline Light or moderate activity (assembly line & $45(17.85)$ \\
\hline work, installers etc) & \\
\hline Heavy-activity (steelmaking, agriculture etc) & $6(2.38)$ \\
\hline \multicolumn{2}{|l|}{ Monthly per capita income } \\
\hline$<1,000$ CNY & $13(5.16)$ \\
\hline $1,000-5,999 \mathrm{CNY}$ & $129(51.19)$ \\
\hline $6,000-9,999$ CNY & $64(25.40)$ \\
\hline$>10,000 \mathrm{CNY}$ & $46(18.25)$ \\
\hline \multicolumn{2}{|l|}{ Type of medical insurance } \\
\hline Rural cooperative medical care & $20(7.93)$ \\
\hline Urban medical insurance & $180(71.43)$ \\
\hline Self-funded & $52(20.64)$ \\
\hline Disease characteristics & n (\%) \\
\hline \multicolumn{2}{|l|}{ Disease } \\
\hline SLE & $|2|(48.02)$ \\
\hline RA & $70(27.78)$ \\
\hline AS & $61(24.21)$ \\
\hline \multicolumn{2}{|l|}{ Disease duration } \\
\hline$<$ I year & $52(20.63)$ \\
\hline $1-5$ years & $102(40.47)$ \\
\hline$\geq 5$ years & $98(38.89)$ \\
\hline \multicolumn{2}{|l|}{ Comorbidities } \\
\hline 0 & $115(45.63)$ \\
\hline $1-2$ & I I 3 (44.84) \\
\hline$\geq 3$ & $24(9.52)$ \\
\hline EQ-5D index, mean (SD) & $0.76(0.17)$ \\
\hline Treatment characteristics & n (\%) \\
\hline Types of pills prescribed daily, mean (SD) & $4.16(2.21)$ \\
\hline Use of GC & $159(63.10)$ \\
\hline Number of DMARDs, mean (SD) & $1.38(0.72)$ \\
\hline Use of NSAIDs & $66(26.19)$ \\
\hline Use of biological DMARDs & $35(13.89)$ \\
\hline \multicolumn{2}{|l|}{ Daily dosing frequency } \\
\hline$<$ Once daily & $14(5.56)$ \\
\hline Once daily & $27(|0.7|)$ \\
\hline Twice daily & $143(56.74)$ \\
\hline Thrice daily & $63(25.00)$ \\
\hline$>$ Thrice daily & $5(1.98)$ \\
\hline \multicolumn{2}{|l|}{ Side effects } \\
\hline 0 & $66(26.19)$ \\
\hline $1-2$ & $164(65.08)$ \\
\hline$\geq 3$ & $22(8.73)$ \\
\hline CQRI9, mean (SD) & $75.84(11.59)$ \\
\hline Use of tools such as medication reminders & $140(55.56)$ \\
\hline Use of alternative medicines & $98(38.89)$ \\
\hline
\end{tabular}

Abbreviations: AS, ankylosing spondylitis; CQR, Compliance Questionnaire for Rheumatology; DMARDs, disease modifying antirheumatic drugs; EQ-5D, EuroQol five dimensions; GC, glucocorticoid; NSAIDs, non-steroidal anti-inflammatory drugs: RA, rheumatoid arthritis; SLE, systemic lupus erythematosus. 
diseases (Table 1). A total of 102 patients (40.5\%) had disease durations of 1 to 5 years. Most patients had no comorbidities (45.6\%) or 1-2 comorbidities (44.8\%). The overall mean EQ-5D index was $0.76( \pm 0.17)$.

Analysis of treatments indicated that these patients took an average of $4.16( \pm 2.21)$ types of drugs daily. The most commonly used drugs were GCs (63.1\%), NSAIDs (26.2\%), and biological DMARDs (13.9\%). These patients also received an average of $1.38( \pm 0.72)$ different kinds of traditional DMARDs, and $56.7 \%$ of patients took medicines twice daily. The mean CQR score was $75.8( \pm 11.6), 55.56 \%$ of subjects used medication reminders, and $38.9 \%$ used an alternative treatment (traditional Chinese medicine, physical therapy, herbs, etc.).

\section{Disease burden}

Among all 252 patients, the annual direct cost per patient was 26,942 $( \pm 55,455) \mathrm{CNY}$ (Table 2). These direct costs consisted of outpatient costs of 9,333 ( $\pm 16,367) \mathrm{CNY}$, hospitalization costs of $14,711( \pm 52,205) \mathrm{CNY}$, and nonmedical costs (such as transportation to clinics and hotel expenses) of 2,898 ( $\pm 8,351) \mathrm{CNY}$. The overall annual indirect cost per patient was $6,634( \pm 25,578)$ CNY. Separate analysis of RA, SLE, and AS patients indicated that SLE patients had the greatest economic burden (direct annual cost per patient: $33,899 \pm 73,278 \mathrm{CNY}$, indirect annual cost per patient: $8,993 \pm 28,139 \mathrm{CNY}$ ). Moreover, $4.84 \%$ of AS patients, $7.37 \%$ of SLE patients, and $16.9 \%$ of RA patients had total direct medical costs that were greater than their annual household incomes.

\section{Adherence and quality of life}

Analysis of treatment adherence, based on CQR results and personal interviews, indicated large variations among our patients (Table 3). More specifically, $48.4 \%$ patients overall had a good medication adherence, based on a CQR of $80 \%$ or more, and $41.7 \%$ of patients reported never having forgotten to take a medication, based on face-to-face interviews. Among patients who reported sometimes forgetting a dose (medication problem no 2), 17 cases were found difficult to be identified by CQR, "I was busy that time, so I missed the time to take the medicines. But I would remember to take

Table 2 Disease burden and adherence ${ }^{a}$ of patients with rheumatic diseases $(n=252)$

\begin{tabular}{|c|c|c|c|}
\hline & Total & Adherent & Nonadherent \\
\hline \multicolumn{4}{|l|}{ All patients (CNY/year) } \\
\hline Direct cost, mean (SD) & $26,942.10(55,455.02)$ & $30,950.17(70,447.23)$ & $23,180.68(36,043.77)$ \\
\hline Outpatient & $9,333.02(16,367.63)$ & $9,973.77(15,983.10)$ & $8,731.71(16,759.82)$ \\
\hline Hospitalization & $|4,7||.5|(52,204.57)$ & I8,250.82 (67,644.II) & II,390.00 (31,429.68) \\
\hline Non-medical & $2,897.57(8,350.65)$ & $2,725.58(6,420.65)$ & $3,058.98(9,846.85)$ \\
\hline Indirect cost, mean (SD) & $6,633.73(25,578.30)$ & $6,235.25(22,062.18)$ & $7,007.69(28,568.36)$ \\
\hline Beyond annual household income, n (\%) & $24(9.49)$ & $14(1 \mathrm{I} .10)$ & $10(7.69)$ \\
\hline \multicolumn{4}{|l|}{ SLE patients (CNY/year) } \\
\hline Direct cost, mean (SD) & $33,899.49(73,277.78)$ & $37,945.14(95,359.95)$ & $30,049.60(43,428.34)$ \\
\hline Outpatient & $7,009.13(8,252.41)$ & $7,663.05(8,276.01)$ & $63,86.85(8,248.68)$ \\
\hline Hospitalization & I5,682.23 (36,9| I.15) & $27,889.83(94,643.66)$ & $20,785.48(42,642.21)$ \\
\hline Non-medical & $2,640.77(4,861.53)$ & $2,392.25(4,249.73)$ & $2,877.26(5,404.20)$ \\
\hline Indirect cost, mean (SD) & $8,992.56(28,139.07)$ & $9,500.00(29,549.13)$ & $8,509.68(26,962.16)$ \\
\hline Beyond annual household income, n (\%) & $9(7.37)$ & $6(10.00)$ & $3(4.84)$ \\
\hline \multicolumn{4}{|l|}{ AS patients (CNY/year) } \\
\hline Direct cost, mean (SD) & $21,453.59(29,035.60)$ & $27,609.33(33,327.80)$ & $15,496.42(23,191.61)$ \\
\hline Outpatient & |3,309.54 (21,804.46) & |7,87|.07 (26, | 22.09) & $8,895.16(15,821.10)$ \\
\hline Hospitalization & $3,878.69(9,463.4 I)$ & $4,936.67(10,049.34)$ & $2,854.84(8,904.30)$ \\
\hline Non-medical & $4,265.36(13,107.43)$ & $4,801.60(10,979.86)$ & $3,746.42(15,050.08)$ \\
\hline Indirect cost, mean (SD) & $3,134.43(10,579.7 I)$ & $3,753.33(10,480.81)$ & $2,535.48(10,813.00)$ \\
\hline Beyond annual household income, n (\%) & $3(4.84)$ & $2(6.45)$ & I (3.22) \\
\hline \multicolumn{4}{|l|}{ RA patients (CNY/year) } \\
\hline Direct cost, mean (SD) & 19,698.61 $(30,829.78)$ & $21,481.15(32,922.25)$ & $18,108.78(29,202.56)$ \\
\hline Outpatient & $9,884.79(20,467.36)$ & $6,925.70(12,063.45)$ & $12,523.97(25,658.80)$ \\
\hline Hospitalization & $7,664.29(19,058.40)$ & |3,|2|.2| (24,707.99) & $2,797.30(10,093.63)$ \\
\hline Non-medical & $2,149.54(7,799.47)$ & $\mathrm{I}, 434.24(2,815.46)$ & $2,787.51(10,424.05)$ \\
\hline Indirect cost, mean (SD) & $5,605.71(29,730.60)$ & $2,654.55(10,940.78)$ & $8,237.84(39,656.69)$ \\
\hline Beyond annual household income, n (\%) & $12(16.90)$ & $6(18.18)$ & $6(16.21)$ \\
\hline
\end{tabular}

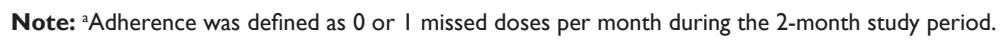

Abbreviations: AS, ankylosing spondylitis; RA, rheumatoid arthritis; SLE, systemic lupus erythematosus. 
Table 3 Medication problems, EQ-5D score, and CQRI9 score of patients with rheumatic diseases $(n=252)^{a}$

\begin{tabular}{lllll}
\hline MP no & AS (\%) & RA (\%) & SLE (\%) & Total (\%) \\
\hline 1 & 16.39 & 11.43 & 18.18 & 15.87 \\
2 & 24.59 & 22.86 & 40.49 & 31.74 \\
3 & 8.20 & 1.43 & 8.26 & 6.34 \\
4 & 9.83 & 11.43 & 16.53 & 13.49 \\
EQ-5D (mean) & 0.792 & 0.700 & 0.780 & 0.761 \\
CQR $\geq 80(\%)$ & 49.18 & 47.14 & 48.76 & 48.41 \\
Adherence (\%) & 31.14 & 38.57 & 48.76 & 41.67 \\
\hline
\end{tabular}

Notes: ${ }^{a}$ Adherence was defined as 0 or I missed doses per month during the 2-month study period. MP no I: usage error; MP no 2: missing dose; MP no 3: precautions unknown; MP no 4: adjustment of dosage or cessation of medicine. Abbreviations: AS, ankylosing spondylitis; CQR, Compliance Questionnaire for Rheumatology; EQ-5D, EuroQol five dimensions; MP, medication problem; RA rheumatoid arthritis; SLE, systemic lupus erythematosus.

my drugs when I went out" (questions 9 and 19 of CQR). Among all medication problems, missing a dose was the main problem (31.7\%). We also found that SLE patients were more likely to stop taking a drug or adjust the dosage (mostly GCs) by themselves (medication problem no 4). RA patients had the lowest EQ-index (mean: 0.700), whereas AS patients had a mean EQ-index of 0.792, and SLE patients had a mean EQ-index of 0.780 .

\section{Univariate analysis of factors associated with adherence}

Table 4 shows the results of a univariate analysis of the effects of different demographic and clinical characteristics on adherence. Among all 252 patients, employment, disease duration, comorbidities, use of a biological DMARD, drug side effects, CQR19 score, and use of tools such as reminders were associated with adherence $(P<0.05$ for all comparisons). Age, sex, marital status, type of medical insurance, comorbidities, and hospitalization were unrelated to adherence ( $P>0.05$ for all comparisons). Analysis of SLE patients indicated that disease duration, comorbidities, drug side effects, and use of tools such as medication reminders were associated with adherence ( $P<0.05$ for all comparisons).

\section{Multivariable logistic regression analysis of factors associated with adherence}

Multivariable logistic regression analysis of all 252 patients indicated that use of tools such as reminders (OR $=2.724$, 95\% CI: 1.381, 5.374, $P<0.01)$, CQR score (OR $=1.034,95 \%$ CI: $1.009,1.060, P<0.01)$, and use of a biological DMARD (OR $=2.185,95 \% \mathrm{CI}: 0.925,5.161, P<0.05)$ were positively associated with adherence (Table 5). Drug side effects $(\mathrm{OR}=0.701,95 \% \mathrm{CI}: 0.516,0.953, P<0.01)$, being employed $(\mathrm{OR}=0.701,95 \% \mathrm{CI}: 0.516,0.953, P<0.01)$, having a light-to-moderate activity job $(\mathrm{OR}=0.111,95 \%$ CI 0.021 , $0.579, P<0.01)$, having a heavy-activity job $(\mathrm{OR}=0.093$, 95\% CI: $0.016,0.535, P<0.01)$, and use of alternative therapies $(\mathrm{OR}=0.483,95 \% \mathrm{CI}: 0.267,0.873, P<0.01)$ were negatively associated with adherence.

We also performed a separate analysis of SLE patients, because they accounted for $48 \%$ of all patients (Table 6). The results indicate that use of tools such as reminders (OR $=6.252$, 95\% CI: 2.530, 15.444, $P<0.01)$ was associated with adherence (Table 6). Moreover, having a heavyactivity job $(\mathrm{OR}=0.214,95 \% \mathrm{CI}: 0.060,0.757, P<0.05)$ and use of alternative therapies $(\mathrm{OR}=0.265,95 \% \mathrm{CI}: 0.109$, $0.645, P<0.01)$ were negatively associated with adherence (Table 6).

\section{Discussion}

To the best of our knowledge, this is the first study to examine the medication adherence and financial burden of patients with rheumatic diseases (AS, RA, and SLE) in China, and also the first to evaluate quality of life using the EQ-5D of patients with SLE and AS in China. We defined adherence as more than one missed dose per month, because CQR only provides an indirect measure of adherence. Among all 252 patients, $41.67 \%$ were adherent, and SLE patients had the best adherence (48.76\%), followed by RA patients (38.57\%), and AS patients (31.14\%). The overall EQ-index of our patients was 0.761; AS patients had the best EQ-index (0.792), followed by SLE patients $(0.780)$, and RA patients (0.700). Thus, although SLE patients had the best adherence, their health status still needs improvement. SLE patients also had greater direct costs than the other two groups (US\$5,103.58 per year).

We found the overall mean CQR score was 75.8 \pm 11.6 , below the cutoff of $80 \%$ used to indicate adherence. This also suggests that our rheumatic disease patients have poor adherence. Previous research indicated the worldwide adherence rate of SLE patients ranged from 3\% to $76 \%$. ${ }^{19}$ Thus, the nonadherence rate in our SLE patients (51.24\%) was lower than in many other parts of the world. Moreover, nonadherence can lead to increased disease activity and

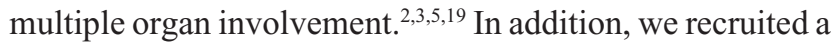
considerable number of SLE patients in this study, and identified predictors of nonadherence. Previous studies differed in their conclusions regarding the factors that are associated with nonadherence. Some researchers argued that barriers to adherence should be assessed on an individual basis, ${ }^{16,20}$ but others identified specific factors associated with adherence in patients with rheumatic diseases, such as education level, 


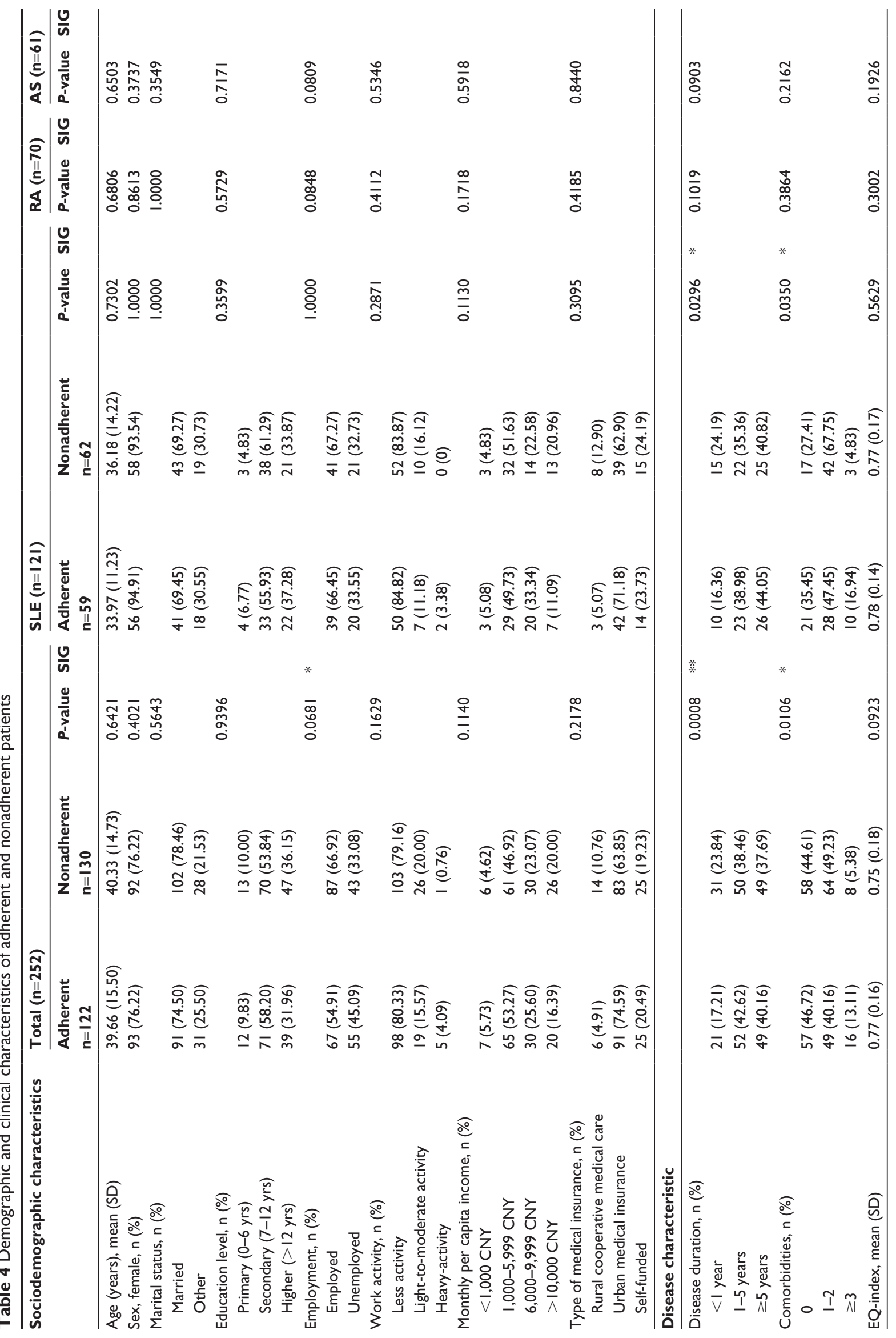




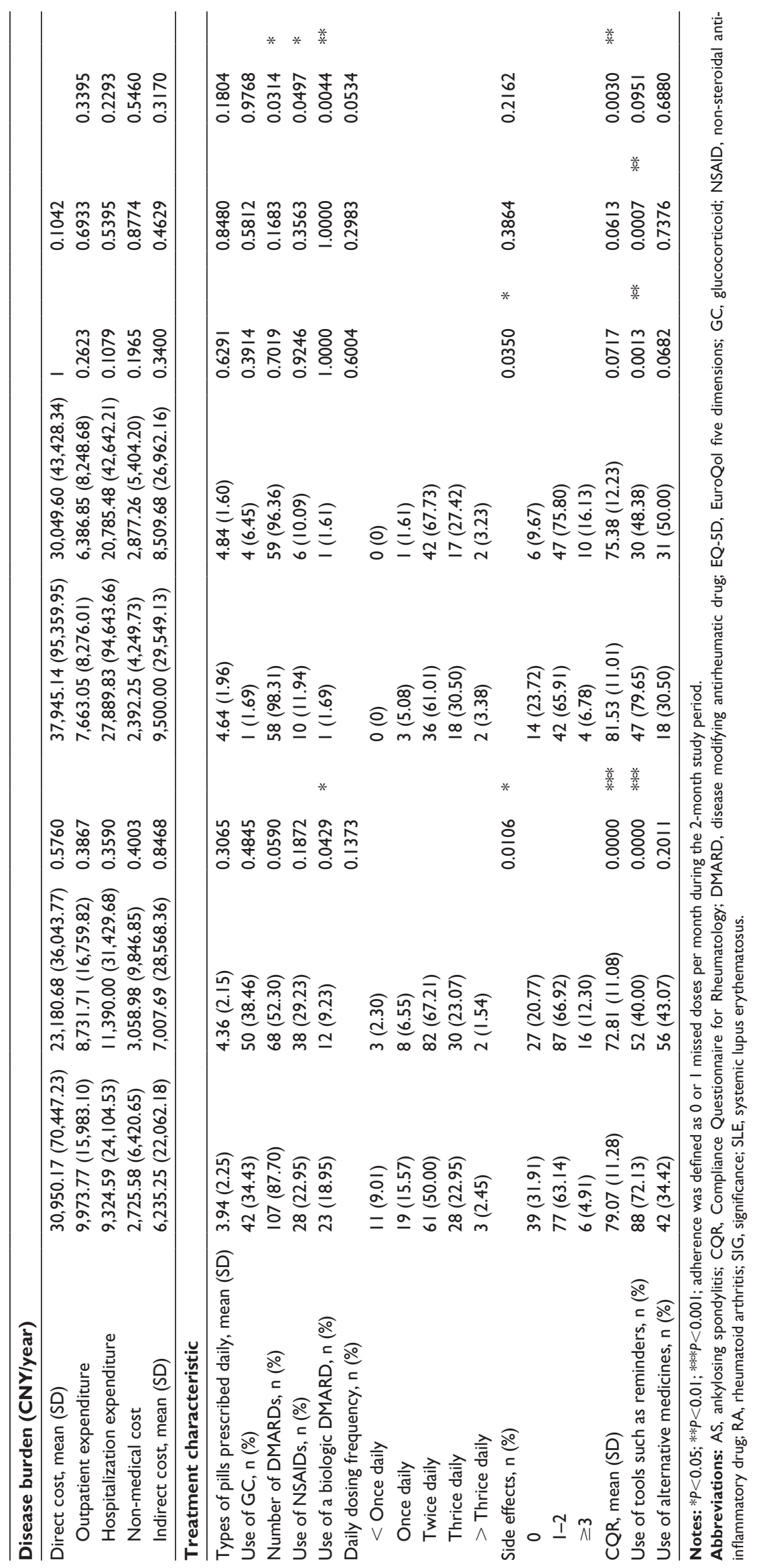


Table 5 Multivariable logistic regression analysis of demographic and clinical characteristics associated with adherence in patients with rheumatic diseases $(n=252)$

\begin{tabular}{|c|c|c|c|c|c|c|}
\hline Characteristic & B & SE & $P$-value & SIG & $\operatorname{Exp}(B)$ & $95 \% \mathrm{Cl}$ \\
\hline \multicolumn{7}{|l|}{ Step $I^{a}$} \\
\hline Use of tools such as reminders & 1.236 & 0.391 & 0.002 & $* *$ & $3.44 I$ & $1.598,7.411$ \\
\hline CQR score & 0.032 & 0.014 & 0.023 & $*$ & 1.032 & $1.004,1.061$ \\
\hline Duration $<$ I year & & & 0.803 & & & \\
\hline $\mathrm{I}-5$ years & -0.178 & 0.429 & 0.678 & & 0.837 & $0.36 \mathrm{I}, 1.939$ \\
\hline$\geq 5$ years & 0.101 & 0.334 & 0.762 & & 1.106 & $0.575,2.128$ \\
\hline Side effects & -0.277 & 0.196 & 0.157 & & 0.758 & $0.517,1.113$ \\
\hline Use of biologic & 0.577 & 0.460 & 0.209 & & $1.78 \mid$ & $0.724,4.384$ \\
\hline No of DMARDs & -0.115 & 0.235 & 0.627 & & 0.892 & $0.562,1.415$ \\
\hline Employed & -0.624 & 0.312 & 0.046 & $*$ & 0.536 & $0.29 I, 0.988$ \\
\hline EQ-5D-index & 1.495 & 0.934 & 0.109 & & 4.459 & $0.715,27.814$ \\
\hline Monthly per capita income $(6,000-9,999$ CNY $)$ & & & 0.285 & & & \\
\hline Monthly per capita income (<I,000 CNY) & 0.053 & 0.779 & 0.945 & & 1.055 & $0.229,4.853$ \\
\hline Monthly per capita income ( $>10,000 \mathrm{CNY})$ & -0.622 & 0.447 & 0.164 & & 0.537 & $0.223,1.289$ \\
\hline Monthly per capita income $(I, 000-5,999$ CNY $)$ & 0.177 & 0.354 & 0.616 & & 1.194 & $0.596,2.390$ \\
\hline Types of pills prescribed daily & -0.291 & 0.212 & 0.170 & & 0.748 & $0.493,1.133$ \\
\hline Work activity, less activity & & & 0.013 & $*$ & & \\
\hline Light-to-moderate activity & -2.911 & 1.020 & 0.004 & $* *$ & 0.054 & $0.007,0.402$ \\
\hline Heavy-activity & -3.097 & 1.058 & 0.003 & $* *$ & 0.045 & $0.006,0.360$ \\
\hline Use of NSAIDs & -0.013 & 0.325 & 0.968 & & 0.987 & $0.522,1.866$ \\
\hline Use of alternative medicines & -0.799 & 0.315 & 0.011 & $*$ & 0.450 & $0.242,0.834$ \\
\hline Type of medical insurance, rural cooperative medical care & & & 0.259 & & & \\
\hline Urban medical insurance & -0.935 & 0.605 & 0.122 & & 0.393 & $0.120,1.284$ \\
\hline Self-funded & 0.142 & 0.369 & 0.701 & & 1.152 & $0.559,20,374$ \\
\hline Comorbidities & 0.243 & 0.152 & 0.132 & & 1.258 & $0.933,1.696$ \\
\hline Hospitalization expenditure & 0.243 & 0.193 & 0.208 & & 1.276 & $0.873,1.863$ \\
\hline \multicolumn{7}{|l|}{ Step $10^{\mathrm{a}}$} \\
\hline Use of tools such as reminders & 1.002 & 0.347 & 0.004 & $* *$ & 2.724 & I.38I, 5.374 \\
\hline CQR scores & 0.034 & 0.013 & 0.007 & $* *$ & 1.034 & $1.009,1.060$ \\
\hline Side effects & -0.355 & 0.157 & 0.023 & $* *$ & 0.701 & $0.516,0.953$ \\
\hline Use of biologics & 0.782 & 0.439 & 0.075 & $*$ & 2.185 & $0.925,5.161$ \\
\hline Employed & -0.654 & 0.293 & 0.026 & $* *$ & 0.520 & $0.293,0.924$ \\
\hline Work activity, less activity & & & 0.026 & $* *$ & & \\
\hline Light-to-moderate activity & -2.202 & 0.845 & 0.009 & $* *$ & 0.111 & $0.02 \mathrm{I}, 0.579$ \\
\hline Heavy-activity & -2.379 & 0.895 & 0.008 & $* *$ & 0.093 & $0.016,0.535$ \\
\hline Use of alternative medicines & -0.727 & 0.302 & 0.016 & $*$ & 0.483 & $0.267,0.873$ \\
\hline
\end{tabular}

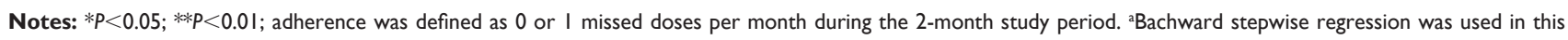
analysis.

Abbreviations: CQR, Compliance Questionnaire for Rheumatology; DMARD, disease modifying antirheumatic drug; EQ, EuroQol; GC, glucocorticoid; NSAID, non-steroidal anti-inflammatory drug; SIG, significance.

marital status, language proficiency, race, comorbidities, high pharmacy costs, taking many pills, number of side effects, missing physician appointments, and quality of life..$^{21-25}$ Our results indicate that side effects and use of alternative medicines were associated with nonadherence in patients with rheumatic diseases, in agreement with previous studies. ${ }^{25-27}$ Our conclusions were somewhat different from those of a previous study, ${ }^{28}$ because we found that working, having a job with light-to-moderate physical intensity (assembly line work, installers, etc.) or heavy physical activity (steelmaking, agriculture, etc.) were associated with nonadherence. The reasons for these findings require further study. We also found that use of a medication reminder tool was associated with increased adherence, in agreement with previous studies. ${ }^{29,30} \mathrm{We}$ found that many patients $(71 / 88)$ reported they missed a dose because they were busy with something else, so reminders may improve adherence in these patients.

Long-term use of certain anti-rheumatic medications may adversely affect the quality of life. More specifically, previous research on Chinese patients with chronic diseases evaluated quality of life using the EQ-5D, and reported an EQ-index 0.79 to 0.94 for patients with diabetes, 0.78 to 0.93 for patients with hypertension, and 0.56 for patients with RA. ${ }^{31}$ To the best of our knowledge, the present study is the first to evaluate quality of life using the EQ-5D in SLE and AS patients from China. We found that the EQ-index 
Table 6 Multivariable logistic regression analysis of demographic and clinical characteristics associated with adherence in SLE patients

\begin{tabular}{|c|c|c|c|c|c|c|}
\hline Characteristic & B & SE & $P$-value & SIG & $\operatorname{Exp}(B)$ & $95 \% \mathrm{Cl}$ \\
\hline \multicolumn{7}{|l|}{ Step $I^{a}$} \\
\hline Monthly per capita income $(6,000-9,999$ CNY $)$ & & & 0.007 & ** & & \\
\hline Monthly per capita income $(<\mathrm{I}, 000 \mathrm{CNY})$ & -0.909 & 1.239 & 0.463 & & 0.403 & $0.036,4.567$ \\
\hline Monthly per capita income ( $>10,000 \mathrm{CNY})$ & -1.889 & 0.763 & 0.013 & $*$ & 0.151 & $0.034,0.674$ \\
\hline Monthly per capita income $(I, 000-5,999$ CNY $)$ & -0.174 & 0.545 & 0.749 & & 0.840 & $0.289,2.444$ \\
\hline Duration $<$ I year & & & 0.794 & & & \\
\hline $\mathrm{I}-5$ years & 0.007 & $0.68 \mathrm{I}$ & 0.992 & & 1.007 & $0.265,3.825$ \\
\hline$\geq 5$ years & 0.315 & 0.514 & 0.540 & & 1.370 & $0.501,3.752$ \\
\hline No of side effects & -0.314 & 0.269 & 0.242 & & 0.731 & $0.432,1.237$ \\
\hline Use of alternative medicines & -1.636 & $0.54 I$ & 0.003 & $* *$ & 0.195 & $0.067,0.563$ \\
\hline CQR scores & 0.038 & 0.025 & 0.130 & & 1.039 & $0.989,1.092$ \\
\hline Comorbidities & 0.494 & 0.240 & 0.040 & $*$ & 0.427 & $0.203,0.896$ \\
\hline Non-medical costs & -0.001 & 0.001 & 0.174 & & 0.999 & $0.998,1.000$ \\
\hline Use of tools such as reminders & 1.334 & 0.722 & 0.065 & & 3.796 & $0.923,15.619$ \\
\hline Hospitalization expenditure & -0.159 & 0.308 & 0.606 & & 0.853 & $0.466,1.560$ \\
\hline Outpatient expenditure & 0.000 & 0.000 & 0.481 & & 1.000 & $0.999,1.000$ \\
\hline Work activity, less activity & & & 0.119 & & & \\
\hline Light-to-moderate activity & -2.488 & 1.744 & 0.154 & & 0.083 & $0.003,2.533$ \\
\hline Heavy-activity & -3.477 & 1.854 & 0.061 & & 0.031 & $0.00 I, 1.171$ \\
\hline \multicolumn{7}{|l|}{ Step $9^{a}$} \\
\hline Work activity, less activity & & & 0.037 & & & \\
\hline Light-to-moderate activity & -0.632 & 0.360 & 0.079 & & 0.532 & $0.263,1.076$ \\
\hline Heavy-activity & -1.543 & 0.645 & 0.017 & $*$ & 0.214 & $0.060,0.757$ \\
\hline Use of tools such as reminders & 1.833 & 0.461 & 0.000 & $* *$ & 6.252 & $2.530,15.444$ \\
\hline Use of alternative medicines & -1.329 & 0.454 & 0.003 & $* *$ & 0.265 & $0.109,0.645$ \\
\hline
\end{tabular}

Notes: $* P<0.05 ; * * P<0.01$. ${ }^{B}$ Bachward stepwise regression was used in this analysis.

Abbreviations: CQR, Compliance Questionnaire for Rheumatology; SIG, significance; SLE, systemic lupus erythematosus.

was best for AS patients (0.792), followed by SLE patients (0.780), and RA patients (0.700). Thus, the health status of RA outpatients in our clinic was better than the average previously reported in China. ${ }^{31}$

Previous studies confirmed that caring for a patient with a chronic condition is a substantial financial burden for the patient and the family. ${ }^{6-8,11,32-34}$ The direct annual costs for an SLE patient can reach up to $€ 4,748$ (US\$5,037) in Europe, up to US\$6,269 in the United States, and costs increase further in those with organ dysfunction (such as lupus nephritis), disease flares, high disease activity, and disease of long duration. ${ }^{8,12,34}$ In our study, the annual direct costs of an SLE patient was 33,899.49 $\pm 73,277.78$ CNY (US\$5,103 $\pm 11,031$ ), and, as indicated by the very large $\mathrm{SD}$, there were large variations among patients, mostly due to differences in comorbidities. The differences of our results compared with those of previous studies might be due to differences in disease activity, duration of disease, and national consumption level. Moreover, we found that the direct costs of a nonadherent patient were less than those of an adherent patient, although the reasons for this finding are uncertain.

We also found differences in adherence from the CQR (48.1\%) and the face-to-face interview (41.7\%). Among patients who reported sometimes forgetting a dose, 17 cases were not identified by the CQR. This finding indicates that the CQR did not measure adherence directly, and could lead to false-positive responses. The interview-based self-report we used probably provides a more accurate measure of adherence. Actually, there is no gold standard for the assessment of treatment adherence, and many methods are used to measure adherence, including the CQR, Morisky medication adherence scale, refill data, medication adherence self-report inventory, pill counting, physician's evaluation, pharmacy refill data, pharmacokinetic markers, and patient interviews. ${ }^{35-41}$ Our results suggest that interview-based self-reports provide a more accurate measure of adherence than the CQR score.

\section{Limitations}

There were some limitations in our work. First, there was a small number of patients, which was partly due to rarity of rheumatic diseases. Second, our patients may not be representative of Chinese patients in general. Further research on this topic should seek to enroll more patients. Nevertheless, our results demonstrate that numerous factors potentially affect drug adherence. More specifically, the use of reminder tools was associated with increased adherence. Thus, use of reminder tools (an alarm clock, mobile phone messages, notepad, SMS, etc.) may be a simple and inexpensive method to increase adherence. 


\section{Conclusion}

In summary, this was the first investigation to study treatment adherence, health status, and financial burden of patients with three types of rheumatic diseases (AS, RA, and SLE), and was also the first to evaluate treatment adherence of SLE and AS patients in China using the CQR. The overall proportion of adherence in our patients was $41.7 \%$, lower than in many other geographic regions. Thus, it is important to identify approaches that improve the treatment adherence of Chinese patients with rheumatic diseases. Our results suggest that use of a reminder tool can improve adherence, but a future interventional study is needed to verify this hypothesis and to identify other measures which could improve adherence. Our results also suggest that it is necessary to further study the health status and disease burden of patients with SLE.

\section{Acknowledgments}

The study was funded by the Shanghai Pharmaceutical Association, 2016 Shanghai Clinical Pharmacy Innovation project (2016-YY-01-12), the Scientific Research Administration Center of Healthcare Qigong of State Physical Culture Administration (QG2016033), and a hospital support project of the South Campus of Renji Hospital (2015QDMS08). We would like to thank the researchers, Minhua Lu and Huiru Wang, who participated in the conceptual formulation and manuscript preparation.

\section{Author contributions}

All authors contributed toward data analysis, writing, and critically revising the paper, and all agree to be accountable for all aspects of the work.

\section{Disclosure}

The authors report no conflicts of interest in this work.

\section{References}

1. Osterberg L, Blaschke T. Adherence to medication. N Engl J Med. 2005; 353(5):487-497.

2. Oliveira-Santos M. Erratum to: Effectiveness of pharmaceutical care for drug treatment adherence in patients with systemic lupus erythematosus in Rio de Janeiro, Brazil: study protocol for a randomized controlled trial. Trials. 2017;18(1):96.

3. Silva CA, Aikawa NE, Pereira RM, Campos LM. Management considerations for childhood-onset systemic lupus erythematosus patients and implications on therapy. Expert Rev Clin Immunol. 2016;12(3): 301-313.

4. Prudente LR, Diniz JS, Ferreira TX, et al. Medication adherence in patients in treatment for rheumatoid arthritis and systemic lupus erythematosus in a university hospital in Brazil. Patient Prefer Adherence. 2016;10:863-870.

5. Lawson EF, Trupin L, Yelin EH, Yazdany J. Reasons for failure to receive pneumococcal and influenza vaccinations among immunosuppressed patients with systemic lupus erythematosus. Semin Arthritis Rheum. 2015;44(6):666-671.
6. Jonsen A, Bengtsson AA, Hjalte F, Petersson IF, Willim M, Nived O. Total cost and cost predictors in systemic lupus erythematosus: 8-years follow-up of a Swedish inception cohort. Lupus. 2015;24(12):1248-1256.

7. Bexelius C, Wachtmeister K, Skare P, Jonsson L, Vollenhoven R. Drivers of cost and health-related quality of life in patients with systemic lupus erythematosus (SLE): a Swedish nationwide study based on patient reports. Lupus. 2013;22(8):793-801.

8. Doria A, Amoura Z, Cervera R, et al. Annual direct medical cost of active systemic lupus erythematosus in five European countries. Ann Rheum Dis. 2014;73(1):154-160.

9. Cho JH, Chang SH, Shin NH, et al. Costs of illness and quality of life in patients with systemic lupus erythematosus in South Korea. Lupus. 2014;23(9):949-957.

10. Pierotti F, Palla I, Pippo L, Lorenzoni V, Turchetti G. Budget impact analysis of belimumab in treating systemic lupus erythematosus. Int $J$ Technol Assess Health Care. 2016;32(5):348-354.

11. Garris C, Jhingran P, Bass D, Engel-Nitz NM, Riedel A, Dennis G. Healthcare utilization and cost of systemic lupus erythematosus in a US managed care health plan. J Med Econ. 2013;16(5):667-677.

12. Carter EE, Barr SG, Clarke AE. The global burden of SLE: prevalence, health disparities and socioeconomic impact. Nat Rev Rheumatol. 2016;12(10):605-620.

13. The Chinese Medical Association of Rheumatology. Guidelines for the diagnosis and treatment of rheumatoid arthritis. Chinese Journal of Rheumatology. 2010;14:265-270.

14. Huang F. [Advances in spondyloarthritis: pathogenesis and treatment]. Basic \& Clinical Medicine. 2005;25:780-784. Chinese.

15. de Klerk E, van der Heijde D, Landewe R, van der Tempel H, van der Linden $\mathrm{S}$. The compliance-questionnaire-rheumatology compared with electronic medication event monitoring: a validation study. J Rheumatol. 2003;30(11):2469-2475.

16. van den Bemt BJ, van den Hoogen FH, Benraad B, Hekster YA, van Riel PL, van Lankveld W. Adherence rates and associations with nonadherence in patients with rheumatoid arthritis using disease modifying antirheumatic drugs. J Rheumatol. 2009;36(10):2164-2170.

17. Liu GG, Wu H, Li M, Gao C, Luo N. Chinese time trade-off values for EQ-5D health states. Value Health. 2014;17(5):597-604.

18. Jorgensen TS, Turesson C, Kapetanovic M, et al. EQ-5D utility, response and drug survival in rheumatoid arthritis patients on biologic monotherapy: A prospective observational study of patients registered in the south Swedish SSATG registry. PLoS One. 2017;12(2): e169946.

19. Costedoat-Chalumeau N, Pouchot J, Guettrot-Imbert G, et al. Adherence to treatment in systemic lupus erythematosus patients. Best Pract Res Clin Rheumatol. 2013;27(3):329-340.

20. Hromadkova L, Soukup T, Cermakova E, Vlcek J. Drug compliance in patients with systemic scleroderma. Clin Rheumatol. 2012;31(11): $1577-1583$.

21. Garcia-Gonzalez A, Richardson M, Garcia Popa-Lisseanu M, et al. Treatment adherence in patients with rheumatoid arthritis and systemic lupus erythematosus. Clin Rheumatol. 2008;27(7):883-889.

22. Hromadkova L, Soukup T, Vlcek J. Quality of life and drug compliance: their interrelationship in rheumatic patients. J Eval Clin Pract. 2015;21(5):919-924.

23. De Cuyper E, De Gucht V, Maes S, Van Camp Y, De Clerck LS. Determinants of methotrexate adherence in rheumatoid arthritis patients. Clin Rheumatol. 2016;35(5):1335-1339.

24. Barton JL, Schmajuk G, Trupin L, et al. Poor knowledge of methotrexate associated with older age and limited English-language proficiency in a diverse rheumatoid arthritis cohort. Arthritis Res Ther. 2013; 15(5):R157.

25. Singh JA. Facilitators and barriers to adherence to urate-lowering therapy in African-Americans with gout: a qualitative study. Arthritis Res Ther. 2014;16(2):R82.

26. Daleboudt GM, Broadbent E, McQueen F, Kaptein AA. Intentional and unintentional treatment nonadherence in patients with systemic lupus erythematosus. Arthritis Care Res (Hoboken). 2011;63(3):342-350. 
27. Xia Y, Yin R, Fu T, et al. Treatment adherence to disease-modifying antirheumatic drugs in Chinese patients with rheumatoid arthritis. Patient Prefer Adherence. 2016;10:735-742.

28. Gross R, Graybill J, Wahezi D, Jordan NC, Putterman C, Blanco I. Increased education is associated with decreased compliance in an urban multi-ethnic lupus cohort. J Clin Cell Immunol. 2014;5(3):pii. 215.

29. Bruera S, Barbo AG, Lopez-Olivo MA. Use of medication reminders in patients with rheumatoid arthritis. Rheumatol Int. 2016;36(11): 1543-1548.

30. Fenerty SD, West C, Davis SA, Kaplan SG, Feldman SR. The effect of reminder systems on patients' adherence to treatment. Patient Prefer Adherence. 2012;6:127-135.

31. Zhou Ting, Guan Haijing, Gordon G, Liu, et al. [Health-related quality of life for disease population in China based on EQ-5D: a systematic review]. Chin J Evid Based Med. 2016;16:135-142. Chinese.

32. Zhu TY, Tam LS, Lee VW, Lee KK, Li EK. The impact of flare on disease costs of patients with systemic lupus erythematosus. Arthritis Rheum. 2009;61(9):1159-1167.

33. Li T, Carls GS, Panopalis P, Wang S, Gibson TB, Goetzel RZ. Longterm medical costs and resource utilization in systemic lupus erythematosus and lupus nephritis: a five-year analysis of a large medicaid population. Arthritis Rheum. 2009;61(6):755-763.

34. Carls G, Li T, Panopalis P, et al. Direct and indirect costs to employers of patients with systemic lupus erythematosus with and without nephritis. J Occup Environ Med. 2009;51(1):66-79.
35. Rauscher V, Englbrecht M, van der Heijde D, Schett G, Hueber AJ High degree of nonadherence to disease-modifying antirheumatic drugs in patients with rheumatoid arthritis. J Rheumatol. 2015;42(3): 386-390.

36. Jorgensen TS, Kristensen LE, Christensen R, et al. Effectiveness and drug adherence of biologic monotherapy in routine care of patients with rheumatoid arthritis: a cohort study of patients registered in the Danish biologics registry. Rheumatology (Oxford). 2015;54(12): 2156-2165.

37. Waimann CA, Marengo MF, de Achaval S, et al. Electronic monitoring of oral therapies in ethnically diverse and economically disadvantaged patients with rheumatoid arthritis: consequences of low adherence. Arthritis Rheum. 2013;65(6):1421-1429.

38. Duvdevany I, Cohen M, Minsker-Valtzer A, Lorber M. Psychological correlates of adherence to self-care, disease activity and functioning in persons with systemic lupus erythematosus. Lupus. 2011;20(1):14-22.

39. Koneru S, Kocharla L, Higgins GC, et al. Adherence to medications in systemic lupus erythematosus. J Clin Rheumatol. 2008;14(4): 195-201.

40. Koneru S, Shishov M, Ware A, et al. Effectively measuring adherence to medications for systemic lupus erythematosus in a clinical setting. Arthritis Rheum. 2007;57(6):1000-1006.

41. Hill J, Bird H, Johnson S. Effect of patient education on adherence to drug treatment for rheumatoid arthritis: a randomised controlled trial. Ann Rheum Dis. 2001;60(9):869-875.
Patient Preference and Adherence

\section{Publish your work in this journal}

Patient Preference and Adherence is an international, peer-reviewed, open access journal that focuses on the growing importance of patient preference and adherence throughout the therapeutic continuum. Patient satisfaction, acceptability, quality of life, compliance, persistence and their role in developing new therapeutic modalities and compounds to optimize

\section{Dovepress}

clinical outcomes for existing disease states are major areas of interest for the journal. This journal has been accepted for indexing on PubMed Central. The manuscript management system is completely online and includes a very quick and fair peer-review system, which is all easy to use. Visit http://www. dovepress.com/testimonials.php to read real quotes from published authors. 